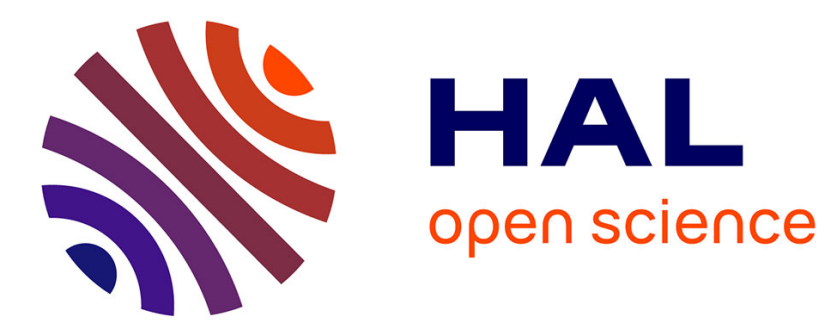

\title{
Methodology of adaptation of the STICS model to a new crop: spring linseed (Linum usitatissimum, L.)
}

Francis Flénet, Pierre Villon, Francoise Ruget

\section{To cite this version:}

Francis Flénet, Pierre Villon, Francoise Ruget. Methodology of adaptation of the STICS model to a new crop: spring linseed (Linum usitatissimum, L.). Agronomie, 2004, 24 (6-7), pp.367-381. 10.1051/agro:2004032 . hal-00886022

\section{HAL Id: hal-00886022 https://hal.science/hal-00886022}

Submitted on 1 Jan 2004

HAL is a multi-disciplinary open access archive for the deposit and dissemination of scientific research documents, whether they are published or not. The documents may come from teaching and research institutions in France or abroad, or from public or private research centers.
L'archive ouverte pluridisciplinaire HAL, est destinée au dépôt et à la diffusion de documents scientifiques de niveau recherche, publiés ou non, émanant des établissements d'enseignement et de recherche français ou étrangers, des laboratoires publics ou privés. 


\title{
Methodology of adaptation of the STICS model to a new crop: spring linseed (Linum usitatissimum, L.)
}

\author{
Francis FLÉNET ${ }^{a *}$, Pierre VILLON ${ }^{\mathrm{b}}$, Françoise RUGET \\ a AlternatecH, Section Agro-Transfert, Chaussée Brunehaut, Estrées-Mons, BP 136, 80203 Peronne Cedex, France \\ ${ }^{\mathrm{b}}$ Université de Technologie de Compiègne, Département G.S.M, BP 20529, 60205 Compiègne Cedex, France \\ ${ }^{\mathrm{c}}$ Unité Climat, Sol et Environnement, INRA, Domaine Saint Paul, Site Agroparc, 84914 Avignon Cedex 9, France
}

(Received 5 June 2003; accepted 10 May 2004)

\begin{abstract}
The STICS simulation model was adapted for linseed. An original procedure was used. Firstly, options were selected from among the possibilities available in STICS to simulate the processes of crops. Secondly, the model was calibrated following six steps: 1. gathering of information, 2. the use of parameters from the literature or from other models, 3. the use of STICS parameters for other crops if there is an analogy with linseed, 4. the use of the experimental data to determine parameters which can be measured or calculated, 5 . the use of the experimental data to determine parameters by testing a range of values, and 6 . the checking of consistency between the parameters and their physical or biological meaning. After adaptation to linseed, the simulations of leaf area, biomass, water consumption, plant nitrogen content, seed number and seed yield were in good agreement with the measurements used for calibration. Thirdly, the results of calculations by STICS were compared with measurements not used for calibration. There was little difference between calculations and measurements of leaf area, biomass, plant nitrogen content and seed number, while seed yield was overestimated because of diseases and lodging, which are not taken into account by the model. However, the differences in seed yield between treatments were properly simulated. This work was a first step towards developing a model to improve linseed crop management. To this end, modifications are needed to account for all yield limitations.
\end{abstract}

linseed / modeling / calibration / validation / STICS

\section{INTRODUCTION}

Linseed (Linum usitatissimum, L.) is an industrial crop. Grains are mainly triturated to extract the oil, which is used for linoleum, paper ink, soap, etc., while the oil cake is used for animal food. The industries of the European Union (E.U.) need 240000 tons of linseed oil per year [11]. Linseed grains are also used whole for animal and human food. The cultivation of linseed in the E.U. has been erratic [25]. This has prevented the development of the utilization of linseed. The main reason for the lack of interest of the European farmers is the low income provided by this crop [12]. The mean yield of linseed in France is about 2 tons ha ${ }^{-1}$, while the maximum yield is 4 tons ha ${ }^{-1}$. An increase in the mean yield, and thus in the income for farmers, would make possible the development of the production of linseed grains in France. This would increase the diversity of cropping systems and hence make the control of diseases and weeds easier. This would also provide a new outlet for French agriculture. A study was conducted in the region of Picardie (France) from 1997 to 2002 in order to promote linseed among farmers and increase their income by improving crop management. First, yield-limiting factors were investigated. Second, this information was used to improve crop management. Experiments were conducted in a limited range of climatic and soil conditions. A crop simulation model would be helpful to explore a wider range of conditions. Moreover, it could be used to investigate yield-limiting factors better.

Few studies have been conducted on linseed crop modeling. The crop parameters to calculate plant biomass and seed yield were derived from field experiments [9]. Some of these parameters were also calculated in other studies, on linseed [19] or on fiber flax [20]. The SUCROS model was adapted to linseed in order to predict the potential yields [5]. However, this model did not account for the effect of water or nitrogen stresses. The SUCROS model was used to understand yield variability better [6]. The ratio between measurements and simulations was used to indicate the effect of water stress on yield. However, the difference between the two may have resulted from other limiting factors. The calculation by the model of water and nitrogen stresses would have provided useful information to examine more accurately the limiting factors. The parameters to simulate these effects are not available in the literature. Moreover, the climatic conditions in the region of Picardie (France) are different from those of the previous studies. Thus, further studies are needed to develop a linseed crop model for agricultural use in the region of Picardie (France).

STICS is a generic model for simulating crops and their water and nitrogen balances. It computes agricultural data (yield and input consumption) as well as environmental data (water and nitrate leaching) in various agricultural situations.

* Corresponding author: francis.flenet@ alternatech.org 
Table I. Options in STICS 4.0.

\begin{tabular}{|c|c|c|}
\hline Modules & Options available & Choices made for linseed \\
\hline \multirow[t]{3}{*}{ Development } & Air temperature or crop temperature to calculate temperature sum & Air temperature \\
\hline & Effect of photoperiod (yes/no) & No \\
\hline & Effect of water stress (yes/no) & No \\
\hline \multirow[t]{4}{*}{ Shoot growth } & $\begin{array}{l}\text { Minimum temperature for increase in biomass different from the minimum temperature for } \\
\text { increase in leaf area (yes/no) }\end{array}$ & Yes \\
\hline & $\begin{array}{l}\text { Radiation-use efficiency during the juvenile stage different from the radiation-use efficiency } \\
\text { afterwards (yes/no) }\end{array}$ & Yes \\
\hline & Absorption of solar radiation by a homogeneous leaf area (Beer's law), or by a raw crop & Homogeneous leaf area \\
\hline & Simulation of biomass senescence (yes/no) & No \\
\hline Nitrogen metabolism & $\mathrm{N}_{2}$ fixation (yes/no) & No \\
\hline \multirow[t]{4}{*}{ Yield components } & Determinate or indeterminate crop & Determinate \\
\hline & Harvest index increases with days or with temperature sum & Daily increase \\
\hline & There is a maximum seed number (yes/no) & No \\
\hline & High temperature affects seed filling (yes/no) & No \\
\hline \multirow[t]{3}{*}{ Root growth } & Crop temperature or soil temperature to calculate temperature sums & Soil temperature \\
\hline & Soil moisture affects root growth (yes/no) & Yes \\
\hline & Roots are simulated as a 'root profile' or as a root density & 'Root profile' \\
\hline \multirow[t]{2}{*}{ Water requirements } & Evapotranspiration is simulated with a crop coefficient or with a resistance approach & Crop coefficient \\
\hline & The interception of rain by the canopy is simulated (yes/no) & No \\
\hline
\end{tabular}

The crop is globally characterized by its aboveground biomass (carbon and nitrogen) and leaf area index, as well as by the number and mass of harvested organs. Vegetative organs (leaves, ramifications or stems) are viewed as a whole. The soil is considered as a succession of horizontal layers characterized by their water, mineral nitrogen, and organic nitrogen content. The STICS model is based on three types of functions:

- a physiological calendar defines the growing stages (development module), using a thermal (degree-day), photothermal, or vernalo-photothermal index according to the species;

- the crop growth functions (leaf area setting, light absorption, conversion of absorbed light and partition to grain) depend on climatic variables (temperature and radiation);

- functions to simulate the effects of water and nitrogen stresses. They require root growth in order to access the water and nitrogen resources (rooting, water balance, mineralization and nitrogen balance).

The model runs using input and parameter files. Parameters describe plant functioning, while input data files contain climate data, initial conditions of crop or soil, permanent conditions of soil and agricultural practices. The model was calibrated [2] and validated [3] for wheat and corn.

STICS is supposed to be adaptable to any crop. An attempt to adapt STICS to linseed was done previously [24], but it appeared that the database was not sufficient. Hence, experiments conducted in the region of Picardie from 1997 to 2002, in order to improve linseed crop management, were used to calibrate and validate the STICS 4.0 model for spring linseed. The adaptation to a new crop is the use of similarities in the framework of the model (equations and their arrangement) and in the parameters of the equations with the crops already simulated. Although 'STICS was conceived as a generic model, able to adapt easily to various kinds of plant' as stated by Brisson et al. [2], the method for adapting this model to a new crop is not well documented. Few studies have investigated the adaptation of a model to a new crop [1,14-16], and only one dealt with STICS [15]. Although these studies give useful information for adapting STICS to a new crop, none of them gives a procedure which should be followed. The objective of this article is to present the procedure used for linseed and the results of this adaptation. All the processes of the model were adapted to linseed, except those used to calculate emergence. Emergence is very variable in linseed crops due to variability in the structural properties of the seed bed. Hence, specific work is being done to simulate emergence with the SIMPLE model [10], as STICS does not account for the structural properties of the seed bed. In the future, these two models will be connected.

\section{MATERIALS AND METHODS}

The adaptation of a model to a new crop is the change in the framework and in the parameters, and the verification that it gives good simulations. The change in parameters is called the calibration of the model. The verification of the quality of the simulations, called validation, is done by comparing simulated values with measurements not used to calibrate the model.

\subsection{Changes in the framework of the model}

The STICS model offers different options to simulate processes of the crop (Tab. I). The choices between options give a range of combinations appropriate for many crops and environmental conditions. Hence, options were selected in order to obtain a particular framework for linseed, according to different criteria. Some choices were made to account for the specific 
features of linseed, some because of the climate of the area of interest, and some others because of the data available. This version of the model is only relevant for spring linseed because there are winter effects on senescence of ramifications which are not well represented in the STICS 4.0 version.

Although an effect of photoperiod on linseed development is reported [17,27], it had no effect on linseed development for a wide range of sowing dates, according to the observations of D'Antuono and Rossini [9] in northern Italy and our own observations in northern France (data not shown), because the same sum of temperature was needed to reach a given stage of development. So, we made the effect of photoperiod ineffective. Furthermore, crop temperature is an additional option, sometimes necessary to explain development, especially when soil is bare and warmer than the air. As the development calendar was well simulated with air temperature (probably because the soil was not dry and hot at the beginning of crop growth), we chose the air temperature. The simulation of an effect of water stress on development also appeared unnecessary. Another option is between determinate and indeterminate formalisms [4]. With the indeterminate formalism, several cycles of flowering can be simulated, and there is a simultaneous leaf setting and grain filling. Although linseed can exhibit several cycles of flowering, the varieties cultivated in France were selected to have one main cycle without competition between leaf setting and grain filling in order not to have a late maturity. Hence, linseed crop could be simulated as a determinate species. The option of two base temperatures, one for the growth in biomass and one for the leaf area development, was selected not because there was a great difference between the two, but for convenience. The calibration of growth in biomass was done after pooling spring and winter linseed data, because it is not variety-dependent. This was done with the base temperature for leaf development of winter linseed $\left(5^{\circ} \mathrm{C}\right)$ and not with that of spring linseed $\left(6{ }^{\circ} \mathrm{C}\right)$.

As the plant rows are narrow, the crop could be simulated as homogenous. Thus, the Beer's law option and the simulation of evapotranspiration with a cultural coefficient were relevant. Senescence of biomass was not simulated because this is an option for perennial species. In order to simulate variability in the harvest indices, it was decided to increase it with days, and not with temperature sums. It also appeared to be useless to fix a maximum seed number or to use the thermal stress-decreasing grain growth at high temperatures (not frequent in northern France).

The calibration of root growth was derived from soil moisture measurements using the 'root profile', which is the ability to take up water. As the upper layers of soil are often dry, the effect of low soil moisture slowing down root growth was selected.

\subsection{Calibration}

The list of parameters and their symbols are in Appendix 1. A six-step procedure was followed to calibrate STICS for linseed: 1 . information gathering, 2 . the use of the information available in the literature or in other models, 3. the determination of parameters by analogy, 4 . by measurements or by calculations, 5 . by testing a range of values, and 6 . the checking of consistency between the parameters and their physical or biological meaning. The order of these steps means that the determination of parameters by analogy was predominant, because the objective of adaptation is to use as much as possible the information on other crops. Then, the determination by measuring or calculating parameters prevailed. Finally, the testing of a range of values was carried out, because with this method of calibration there is a risk of obtaining values of parameters that do not result in the lowest difference between simulations and measurements. Moreover, if a lot of parameters are determined at the same time by testing values, there is a great risk of obtaining values not consistent with their meaning. Other methods are being studied now in order to determine simultaneously some parameters, also using a priori information [18], but they are not convenient for a great number of parameters.

\subsubsection{Information gathering}

All the information available for linseed modeling had to be gathered: the literature (linseed and other crops), models (the STICS model for other crops and linseed models already existing) and the experimental database. The information on linseed is scarce in the literature. However, some parameters for crop modeling are available $[9,19,20,24]$, and some experiment reports provide measurements which can be used [7, 8, 21].

The database results from 13 experiments (Tab. II) conducted in northern France on a silt loam (luvisol orthique, FAO classification: $0.15 \mathrm{~g} \mathrm{~g}^{-1}$ clay, $0.81 \mathrm{~g} \mathrm{~g}^{-1}$ silt and $0.04 \mathrm{~g} \mathrm{~g}^{-1}$ sand) in 1999 and 2002. The database was divided into two parts in order to keep data not used for calibration to validate the model. In 1999, in experiments 1 to 8, fungi had little effect on the plants. The STICS model does not account for the effect of fungus. Hence, it is important to calibrate this model without such diseases. These experiments (numbers 1 to 8), all conducted in the same year and in the same location, were chosen to calibrate the model. In experiments 1 to 6 spring linseed was studied, while winter linseed was sown in experiments 7 and 8. The results were pooled to calibrate the parameters which do not depend on variety. The calibration of the parameters which depend on variety was only done for spring linseed. Hence, the result is a STICS model only calibrated for spring linseed. For the calibration of seed set and seed filling, only measurements on the NIAGARA variety at sowing dates 1 and 2 were used because: 1. lodging, which is not simulated by STICS, was observed on the BAIIKAL variety during seed filling. It resulted in a decreased seed number and seed weight, and 2. the seed set of the third sowing was very poor. It is well known that late sowings result in low yields. For this reason, in northern France linseed is sown by the end of March. For the calibration of seed set, results from the literature $[7,8,21]$ were added to the measurements of experiments 1 to 4 .

Experiments 9 and 10 conducted in 'Domaine de Brunehaut' (Estrées-Mons, $50^{\circ} \mathrm{N}$ latitude, $3^{\circ} \mathrm{E}$ longitude), and experiments 11,12 and 13 , respectively conducted in Berlancourt $\left(50^{\circ} \mathrm{N}\right.$ latitude, $4^{\circ} \mathrm{E}$ longitude $)$, Long $\left(50^{\circ} \mathrm{N}\right.$ latitude, $2^{\circ} \mathrm{E}$ longitude) and Sacy-le-Petit $\left(49^{\circ} \mathrm{N}\right.$ latitude, $3^{\circ} \mathrm{E}$ longitude) were used to validate the model. In Berlancourt and Long, N-fertilizer efficiency was poor, and the plants were $\mathrm{N}$-stressed even with $150 \mathrm{~kg} \mathrm{~N} \mathrm{ha}^{-1}$. The nitrogen-use efficiency was calculated for each of these two experiments, using the differences between 
Table II. Crop management in the experiments.

\begin{tabular}{|c|c|c|c|c|c|c|c|c|c|}
\hline \multirow{2}{*}{$\begin{array}{l}\text { Experiment number } \\
\text { and location }\end{array}$} & \multirow{2}{*}{$\begin{array}{c}\text { Sowing } \\
\text { date }\end{array}$} & \multirow{2}{*}{$\begin{array}{c}\text { Seed } \\
\text { number } \mathrm{m}^{-2}\end{array}$} & \multirow[t]{2}{*}{ Irrigation } & \multicolumn{2}{|c|}{ Fertilizers $\left(\mathrm{kg} \mathrm{ha}^{-1}\right)$} & \multirow{2}{*}{$\begin{array}{l}\text { Growth } \\
\text { regulator }\end{array}$} & \multirow[t]{2}{*}{ Fungicide } & \multirow{2}{*}{$\begin{array}{l}\text { Weed } \\
\text { control }\end{array}$} & \multirow[t]{2}{*}{ Insecticide } \\
\hline & & & & Nitrogen & Others & & & & \\
\hline $\begin{array}{l}\text { Exp. } 1 \text { in Dom. } \\
\text { Brunehaut }\end{array}$ & $03 / 15 / 99$ & 300 or 700 & None & 100 & \multirow{6}{*}{$\begin{array}{l}\text { Phosphorus, } \\
\text { Potassium and } \\
\text { Zinc were } \\
\text { applied in } \\
\text { order to avoid } \\
\text { stress }\end{array}$} & \multirow{4}{*}{$\begin{array}{c}\text { One } \\
\text { application }\end{array}$} & \multirow{10}{*}{$\begin{array}{c}\text { One } \\
\text { application at } \\
\text { the } \\
\text { beginning of } \\
\text { flowering } \\
\text { and one } \\
\text { application at } \\
\text { the end of } \\
\text { flowering }\end{array}$} & \multirow{13}{*}{$\begin{array}{l}\text { Application } \\
\text { of } \\
\text { herbicides, } \\
\text { and hand } \\
\text { hoeing when } \\
\text { necessary }\end{array}$} & \multirow{13}{*}{$\begin{array}{c}\text { Application } \\
\text { when insects } \\
\text { were } \\
\text { observed }\end{array}$} \\
\hline $\begin{array}{l}\text { Exp. } 2 \text { in Dom. } \\
\text { Brunehaut }\end{array}$ & 03/15/99 & $\begin{array}{c}300,700 \text { or } \\
1100\end{array}$ & $\begin{array}{c}\text { To avoid } \\
\text { stress }\end{array}$ & 100 & & & & & \\
\hline $\begin{array}{l}\text { Exp. } 3 \text { in Dom. } \\
\text { Brunehaut }\end{array}$ & 03/29/99 & 300 or 700 & None & 0 or 100 & & & & & \\
\hline $\begin{array}{l}\text { Exp. } 4 \text { in Dom. } \\
\text { Brunehaut }\end{array}$ & 03/29/99 & $\begin{array}{c}300,700 \text { or } \\
1100\end{array}$ & $\begin{array}{c}\text { To avoid } \\
\text { stress }\end{array}$ & 0 or 100 & & & & & \\
\hline $\begin{array}{l}\text { Exp. } 5 \text { in Dom. } \\
\text { Brunehaut }\end{array}$ & 04/19/99 & 300 or 700 & None & 100 & & \multirow{2}{*}{ None } & & & \\
\hline $\begin{array}{l}\text { Exp. } 6 \text { in Dom. } \\
\text { Brunehaut }\end{array}$ & 04/19/99 & $\begin{array}{c}300,700 \text { or } \\
1100\end{array}$ & $\begin{array}{c}\text { To avoid } \\
\text { stress }\end{array}$ & 100 & & & & & \\
\hline $\begin{array}{l}\text { Exp. } 7 \text { in Dom. } \\
\text { Brunehaut }\end{array}$ & 09/02/98 & 150 or 600 & $\begin{array}{c}\text { To avoid } \\
\text { stress }\end{array}$ & \multirow{2}{*}{$\begin{array}{c}0,40,80 \text { or } \\
160\end{array}$} & \multirow{2}{*}{$\begin{array}{l}\text { Phosphorus } \\
\text { and Potassium } \\
\text { but no Zinc }\end{array}$} & $\begin{array}{c}\text { Two } \\
\text { applications }\end{array}$ & & & \\
\hline $\begin{array}{l}\text { Exp. } 8 \text { in Dom. } \\
\text { Brunehaut }\end{array}$ & 09/15/98 & 150 or 600 & $\begin{array}{c}\text { To avoid } \\
\text { stress }\end{array}$ & & & $\begin{array}{c}\text { One } \\
\text { application }\end{array}$ & & & \\
\hline $\begin{array}{l}\text { Exp. } 9 \text { in Dom. } \\
\text { Brunehaut }\end{array}$ & 03/05/02 & \multirow{2}{*}{$\begin{array}{c}100,200 \\
400,600 \text { or } \\
800\end{array}$} & None & \multirow{2}{*}{120} & \multirow{5}{*}{$\begin{array}{l}\text { Phosphorus, } \\
\text { Potassium and } \\
\text { Zinc were } \\
\text { applied in } \\
\text { order to avoid } \\
\text { stress }\end{array}$} & One & & & \\
\hline $\begin{array}{l}\text { Exp. } 10 \text { in Dom. } \\
\text { Brunehaut }\end{array}$ & 03/05/02 & & $\begin{array}{c}\text { To avoid } \\
\text { stress }\end{array}$ & & & application & & & \\
\hline $\begin{array}{l}\text { Exp. } 11 \text { in } \\
\text { Berlancourt }\end{array}$ & $03 / 15 / 99$ & & \multirow{3}{*}{ None } & \multirow{3}{*}{\begin{tabular}{|c}
$0,30,60,90$, \\
120 or 150 at \\
planting, or 45 \\
at planting plus \\
45 one month \\
later
\end{tabular}} & & \multirow[t]{2}{*}{ None } & \multirow{3}{*}{$\begin{array}{c}\text { One } \\
\text { application at } \\
\text { the } \\
\text { beginning of } \\
\text { flowering }\end{array}$} & & \\
\hline Exp. 12 in Long & $03 / 23 / 99$ & & & & & & & & \\
\hline $\begin{array}{l}\text { Exp. } 13 \text { in } \\
\text { Sacy-le-Petit }\end{array}$ & $03 / 17 / 99$ & & & & & $\begin{array}{c}\text { One } \\
\text { application }\end{array}$ & & & \\
\hline
\end{tabular}

plant nitrogen content simulated by STICS and measurements. Then, new simulations were done with the calculated $\mathrm{N}$-fertilizer efficiency as an input variable. The results were used for comparisons with measurements. In 'Domaine de Brunehaut', Septoria linicola developed. It resulted in an early leaf senescence, which affected seed weight but not seed number. Lodging was also observed for BAÏKAL in some treatments, while NIAGARA was not affected. It resulted in a decreased seed number and seed weight. In Long, Berlancourt and Sacy-lePetit, there was no accurate evaluation of fungus development. Hence, greater simulated seed numbers and seed yields than the measurements were expected for all these 5 experiments.

\subsubsection{Parameters in the literature or from other models}

The equations of crop models are derived from the analysis of relationships between the variables of agricultural systems. Hence, the parameters can be found in the literature using these equations to describe experimental results. The adaptation of the CROPGRO model to faba bean [1] and to velvet bean [16], and the methodology of adapting STICS to new crops [15] included the use of parameters from the literature. Other models can also provide the values of parameters because most equations are similar to those of STICS. There was an attempt to use the parameters from the literature to calibrate STICS for linseed. However, it was done carefully because these parameters are often not exactly the same as those used in STICS. There are three reasons for such differences: 1 . the exact meaning of the parameter can be different (for instance, STICS uses the maximum radiation-use efficiency and not the actual radiationuse efficiency usually found in the literature), 2. the range of environmental conditions can be extremely different, and 3 . the varieties of interest may be different.

\subsubsection{Determination of parameters by analogy to other crops}

Some parameters can be determined by analogy to other crops which are similar. Analogy or contrast to other legumes were used to adapt CROPGRO [1, 16]. However, Ghiloufi [15] failed to find analogies in the STICS crop model between groups of species for leaf growth, root growth and the nitrogen dilution curve. The requirements for similarities are greater for parameters which have a great effect on the outputs of interest than for parameters which have little effect. The effect of a given parameter depends on the environmental conditions which prevail for the utilization. In the present work, the STICS model was adapted for northern France. Hence, there were good possibilities of determining by analogy the parameters used to simulate the effects of high temperature and of water stress. A sensitivity analysis provides information on the effect of parameters [26]. Even if the analysis was made for corn and wheat, it studied most of the same parameters, and it pointed out the most influential parameters, such as those of leaf area and root setting, of conversion efficiency, and the importance of maximum soil water availability (field capacity) greater for 
wheat than for corn, while the summer crop (corn) is more sensitive to root growth parameters.

\subsubsection{Determination of parameters from experimental data by measuring or calculating them}

Some parameters can be measured in experiments (for instance, the maximum seed weight) or can be calculated because all the variables of the equation are measured and there is an analytic solution for the parameters. In the adaptation of CROPGRO $[1,16]$ and in the methodology for adapting STICS to new crops [15], there was no such analytic determination of parameters. In the present work we tried to find analytic solutions as much as possible, because it easily provides the parameters with the lowest difference between simulations and measurements. In STICS, four equations which had to be calibrated for linseed were linear functions (or were linear after a LOG transformation): the nitrogen dilution curves, the light extinction curve, and the calculation of seed number and of the harvest index. Hence, the parameters were determined analytically. The temperature sums between stages of development were also calculated, except for AMF (maximum acceleration in the growth of leaf area) because this stage of development cannot be observed.

\subsubsection{Determination of parameters from experimental data by testing a range of values}

The parameters not determined by the methods described previously were determined by testing a range of values and by choosing the values which minimized J, the difference between simulations and measurements $\left(\mathrm{J}=\sum_{\mathrm{j}=1}^{\mathrm{j}=\mathrm{n}}\right.$ (Measurement (Me $_{j}$ Simulated value $\left._{j}\right)^{2}$ ). All these remaining parameters were not determined at the same time, but in groups. In order to avoid too long an iterative procedure, the simulated values which were compared with the measurements only involved equations to be calibrated and equations already calibrated. We tried three tricks to do so: 1 . using a data set which did not need the calculations of all the equations (for instance, a data set without stresses), 2. following an order which took into account the relationships between the modules (Fig. 1), and 3. using measurements to fix the values of some variables. If several parameters are determined at the same time, the number of combinations of values is great and the test of all combinations is difficult. Moreover, if several parameters are determined at the same time, some of the values may be not consistent with their physical or biological meaning. An optimization algorithm may be used in order not to test all the combinations. However, it does not prevent values not consistent with their meanings.

The sensitivity analysis of STICS [26] showed that for a given parameter, some outputs were not very sensitive to its variations. Hence, they should not be used to calibrate this parameter by testing a range of values. The outputs used to calibrate the parameters were chosen from among the most sensitive. The accuracy of the measurements of the outputs may also be of great importance for calibration [26]. Hence, measurements were made with caution in order to obtain accurate values.

The parameters of leaf expansion were determined at the same time as the AMF stage of development. This procedure was a mix of finding an analytical solution and testing a range of values. Although an analytic solution exists for the parameters of leaf growth, it could not be found in the literature. A specific calculation had to be done (see Appendix 2).

\subsubsection{The checking of consistency between the parameters and their physical or biological meaning}

Calibration may provide values not consistent with the meaning of the parameters. This may result in bad simulations under other environmental conditions. Thus, the consistency of parameters with their meaning was checked. For this purpose, the parameters from other crops, from other linseed models and from the literature may be helpful to determine the ranges of possible values.

\subsection{The mathematical criteria to validate the model}

The criteria calculated to validate the model were parameters of the linear regression between simulations and measurements, the root mean square error (RMSE) and the mean deviation (MD): see Brisson et al. [3] for details. The intercept and the slope of the linear regression indicate a bias if the values differ from 0 and 1 , respectively. The coefficient of regression provides an estimation of the reliability of the model. The RMSE indicates the error of prediction of the model by giving more weight to high errors. A low value of RMSE, expressed in \%, means a good prediction ability of the model. The MD gives an estimation of the bias of the model. A low value, expressed in \%, indicates little bias.

\section{RESULTS}

All parameters specific to linseed were determined, using the method and the order of determination summarized in Table III.

\subsection{Calibration}

Linseed parameters available in the literature $[9,19,20,24]$ were examined. It was not possible to use directly the values reported in these articles. The varieties were different, which prevented us from using the parameters to simulate phenology or leaf area. Moreover, most of the parameters of the literature were not exactly the same as in STICS. For instance, in the literature the radiation-use efficiency was calculated in the conditions of the experiments, while STICS needs the maximum value of this parameter.

Parameters used to simulate the effect of high temperatures (TDMAX and TCMAX) were determined by analogy (Tab. III), because in northern France the weather is cool and thus their effect is slight. The values for wheat, a species adapted to a temperate climate like linseed, were used. Likewise, the thresholds for water stress (PSISTO and PSITURG) were set to the values of wheat. The parameter for root growth when soil water is below the wilting point (PROPPFZ) was set to 0 (no growth below the wilting point), because in STICS this is the value used for all annual crops cultivated in France. 


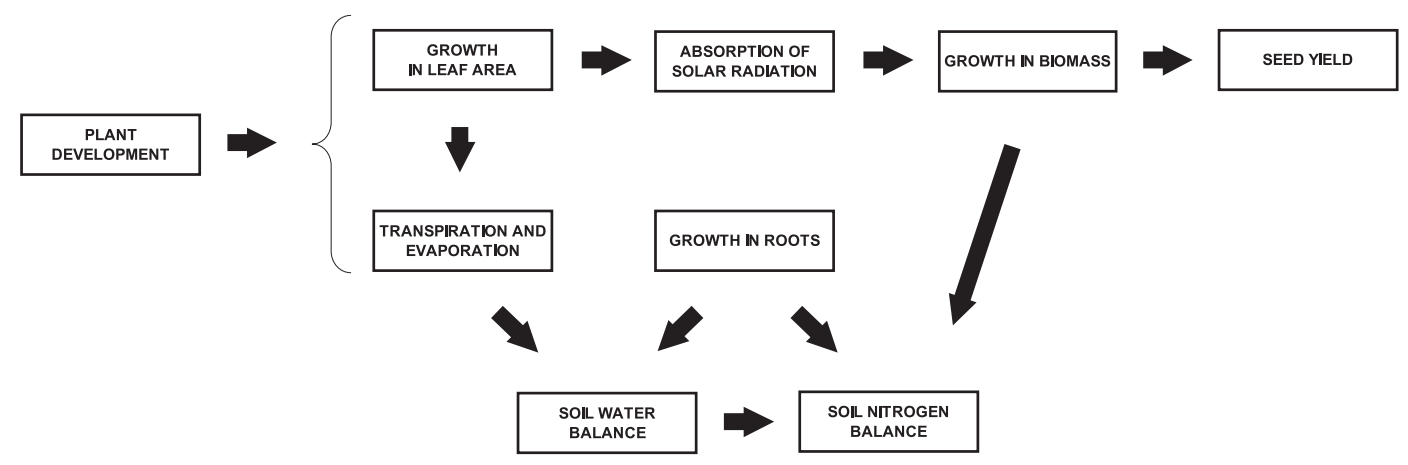

Figure 1. Relationships between the modules of the STICS model when data without nitrogen or water stress are used.

More than half of the parameters were experimental measurements or were determined analytically (Tab. III). The determination of the AMF stage along with the parameters for leaf expansion is detailed below, because a specific calculation was done (see Appendix 2). The test of a range of STLEVAMF values, which is the sum of temperatures between emergence and the AMF stage, is presented in Figure 2. The criterion $\mathrm{J}\left(\mathrm{C}^{*}(\mathrm{~d}\right.$, $\mathrm{T}_{\mathrm{c}}$ ), $\mathrm{T}_{\mathrm{c}}$ ) was calculated (see Eq. (10): $\mathrm{d}$ is plant density and $\mathrm{T}_{\mathrm{c}}$ is STLEVAMF) for different values of STLEVAMF. The whole range of possible values was tested: from 25 degree-days (the AMF stage almost at emergence) to 375 degree-days (the AMF stage almost at the stage when leaf area is maximum). The parameter was set to 175 degree-days, which was the value that minimized this criterion. Then, the values of $C^{*}(d)$, for $T_{c}$ that minimized $\mathrm{J}\left(\mathrm{C}^{*}\left(\mathrm{~d}, \mathrm{~T}_{\mathrm{c}}\right), \mathrm{T}_{\mathrm{c}}\right)$, were used to determine ADENS and DLAIMAX. The coefficients of the linear regression (Fig. 3) between the logarithm of $\mathrm{C}^{*}(\mathrm{~d})$ and the logarithm of $\mathrm{d}$, the plant density, were calculated: $\alpha=0.324$ and $\beta=-6.47$. Then, the parameters were calculated: ADENS $=-0.676$ (see Eq. (13)) and DLAIMAX $=0.00026$ (see Eq. (15)).

The remaining parameters were determined by testing a range of values, and by selecting those which minimized the difference between simulations and measurements. In order to compare measurements with calculated values which only involved the equation to be calibrated and equations already calibrated, a data set which did not need the calculations of all the equations of the model was chosen. Data without water or nitrogen stresses were used for calibration. Moreover, modules were calibrated following an order imposed by the relationship between the modules of STICS (Fig. 1). Hence, the development was calibrated first, followed by the growth in biomass, evapotranspiration, root growth and nitrogen uptake. The measurements which were compared with the simulated variables to calculate J were: the date of the beginning of flowering (to calibrate the base temperature for development), the plant biomass (to calibrate the growth in biomass), evapotranspiration (to calibrate evapotranspiration), soil moisture (to calibrate root growth) and plant nitrogen content (to calibrate nitrogen uptake). Evapotranspiration could be calibrated before root growth, because it only needed the calculations of water balance overall and not the details for each soil layer. The third trick to avoid multiple iterations, the use of measurements to fix the values of some variables, appeared to be unnecessary.
The two parameters to simulate the growth in biomass (EBMAX and TCOPT) had to be determined at the same time, while all other parameters could be determined alone. Thus, there was no need for an optimization algorithm, because all combinations of values could be tested. For the determination of the minimum temperature for development (TDMIN) and of the maximum radiation-use efficiency (EBMAX), the literature was used to choose the range of values to be tested. For instance, in the vegetative phase, the radiation-use efficiency of linseed (between 2.35 and $2.95 \mathrm{~g} \mathrm{MJ}^{-1}$ ) [9, 20] was used to choose the minimum value to be tested and the maximum radiation-use efficiency of wheat $\left(4.25 \mathrm{~g} \mathrm{MJ}^{-1}\right)$ [2] was used to choose the maximum value to be tested.

The consistency of the parameters determined by calculations and by testing a range of values was examined. The maximum rate of the setting up of leaf area index (DLAIMAX) was lower than that of wheat or maize, which is consistent with the poor ability of linseed to cover the ground. Hence, farmers sow linseed at a great plant density compared with that for wheat and for maize. The extinction coefficient (EXTIN) was the same as that for maize and greater than that for wheat. This is the result of a greater leaf-to-stem angle which is more efficient at intercepting solar radiation. The maximum radiation-use efficiencies (EFCROIJUV, EFCROIVEG or EFCROIREPRO) were low. This was also found for the radiation-use efficiency by previous authors $[9,20]$. The maximum radiation-use efficiency was the same at any stage of development, while it should have been lower during seed filling because of the energy cost for oil synthesis $[13,22]$. This was the result of the underestimation of leaf area by the model at the end of the period of growth in the leaf area index (LAI; Fig. 4a). Hence, the calibration of the maximum radiation-use efficiency resulted in an overestimation during seed filling to compensate the low simulated LAI values. A lower maximum radiation-use efficiency during the juvenile phase compared with the vegetative phase was also expected. However, this expectation arose from observations of radiation-use efficiency, and not the maximum value, which could result from a reduction of efficiency due to low temperature at the beginning of crop development. The optimum temperature of growth (TCOPT) for linseed was close to the value for wheat $\left(15^{\circ} \mathrm{C}\right)$ which is a species adapted to a temperate climate like linseed. The maximum crop coefficient for water requirement (KMAX) was greater for linseed 
Table III. The value of parameters with the order and the method of determination.

\begin{tabular}{|c|c|c|c|c|}
\hline PARAMETER & ORDER & METHOD OF DETERMINATION & $\begin{array}{c}\text { VALUES FOR } \\
\text { BAÏKAL }\end{array}$ & $\begin{array}{c}\text { VALUES FOR } \\
\text { NIAGARA }\end{array}$ \\
\hline \multicolumn{5}{|c|}{ DEVELOPMENT } \\
\hline TDMIN $\left({ }^{\circ} \mathrm{C}\right)$ & 3.1 & Test of a range of values & 6 & 6 \\
\hline $\operatorname{TDMAX}\left({ }^{\circ} \mathrm{C}\right)$ & 1 & Analogy to other crops & 28 & 28 \\
\hline STLEVDRP (degree-days) & 3.2 & Calculation & 550 & 496 \\
\hline STDRPMAT (degree-days) & 3.2 & Calculation & 400 & 400 \\
\hline STLEVAMF (degree-days) & 4 & Test of a range of values & 175 & 150 \\
\hline STAMFLAX (degree-days) & 4 & Test of a range of values & 225 & 250 \\
\hline STLAXSEN (degree-days) & 3.2 & Calculation & 385 & 385 \\
\hline STSENLAN (degree-days) & 3.2 & Calculation & 115 & 115 \\
\hline \multicolumn{5}{|c|}{ SHOOT GROWTH } \\
\hline ADENS & 4 & Calculation & -0.68 & -0.42 \\
\hline BDENS (plants $\mathrm{m}^{-2}$ ) & 4 & Measurement & 14 & 21 \\
\hline DLAIMAX $\left(\mathrm{m}^{2}\right.$ leaves $\mathrm{m}^{-2}$ soil degree-day $\left.{ }^{-1}\right)$ & 4 & Calculation & 0.00026 & 0.000088 \\
\hline $\operatorname{SBV}\left(\mathrm{cm}^{2} \mathrm{~g}^{-1}\right)$ & 4 & Choice of a value which results in no effect of SBV & 950 & 950 \\
\hline EXTIN & 2 & Calculation & 0.7 & 0.7 \\
\hline EFCROIJUV $\left(\mathrm{g} \mathrm{MJ}^{-1}\right)$ & 5 & Test of a range of values & 3.1 & 3.1 \\
\hline EFCROIVEG $\left(\mathrm{g} \mathrm{MJ}^{-1}\right)$ & 5 & Test of a range of values & 3.1 & 3.1 \\
\hline EFCROIREPRO $\left(\mathrm{g} \mathrm{MJ}^{-1}\right)$ & 5 & Test of a range of values & 3.1 & 3.1 \\
\hline TCMIN $\left({ }^{\circ} \mathrm{C}\right)$ & 3.1 & The same value as TDMIN & 5 & 5 \\
\hline $\mathrm{TCOPT}\left({ }^{\circ} \mathrm{C}\right)$ & 5 & Test of a range of values & 16 & 16 \\
\hline $\operatorname{TCMAX}\left({ }^{\circ} \mathrm{C}\right)$ & 1 & Analogy to other crops & 40 & 40 \\
\hline \multicolumn{5}{|c|}{ WATER BALANCE } \\
\hline KMAX & 6 & Test of a range of values & 1.8 & 1.8 \\
\hline PSISTO & 1 & Analogy to other crops & 15 & 15 \\
\hline PSITURG & 1 & Analogy to other crops & 4 & 4 \\
\hline \multicolumn{5}{|c|}{ ROOT GROWTH } \\
\hline PROPPFZ & 1 & Analogy to other crops & 0 & 0 \\
\hline ZPRLIM (cm) & 2 & Measurement & 150 & 150 \\
\hline CROIRAC $\left(\mathrm{cm}\right.$ degree-day $\left.{ }^{-1}\right)$ & 7 & Test of a range of values & 0.19 & 0.19 \\
\hline ZPENTE $(\mathrm{cm})$ & 8 & Test of a range of values & 60 & 60 \\
\hline \multicolumn{5}{|c|}{ NITROGEN BALANCE } \\
\hline ADIL (g N g dry matter ${ }^{-1}$ ) & 2 & Calculation & 4.66 & 4.66 \\
\hline BDIL & 2 & Calculation & 0.5 & 0.5 \\
\hline INNMIN & 2 & Measurement & 0.3 & 0.3 \\
\hline MASECNMAX $\left(\mathrm{t} \mathrm{ha}^{-1}\right)$ & 2 & Measurement & 1.5 & 1.5 \\
\hline ADILMAX (g N g dry matter ${ }^{-1}$ ) & 2 & Calculation & 7.22 & 7.22 \\
\hline BDILMAX & 2 & Calculation & 0.5 & 0.5 \\
\hline $\operatorname{VMAX} 2\left(\mu \mathrm{mol} \mathrm{cm}{ }^{-1} \mathrm{~h}^{-1}\right)$ & 9 & Test of a range of values & 0.06 & 0.06 \\
\hline \multicolumn{5}{|c|}{ YIELD COMPONENTS } \\
\hline NBJGRAIN (days) & 1 & Measurement ${ }^{\mathrm{a}}$ & 20 & 20 \\
\hline CGRAIN (grains g dry matter ${ }^{-1}$ day) & 2 & Calculation & 1961 & 1961 \\
\hline CGRAINV0 (grains $\mathrm{m}^{-2}$ ) & 2 & Calculation & 12390 & 12390 \\
\hline PGRAINMAXI (g) & 2 & Measurement & 0.0069 & 0.0086 \\
\hline IRMAX & 2 & Measurement & 0.5 & 0.5 \\
\hline VITICARB ( $\mathrm{g}$ of grain $\mathrm{g}$ plant ${ }^{-1} \mathrm{day}^{-1}$ ) & 2 & Calculation & 0.014 & 0.014 \\
\hline
\end{tabular}

${ }^{\mathrm{a}}$ The number of days to compute the number of grains (NBJGRAIN) was not really measured. It was set to 20 days, which was the average duration of flowering, because in the data set available there were biomass measurements at the beginning and at the end of flowering and because there was a good correlation between seed number and the growth in biomass between these two stages of development. 


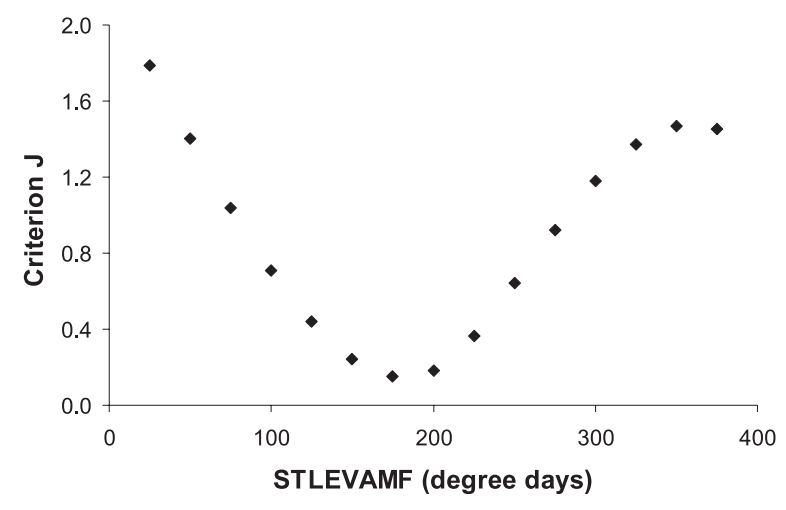

Figure 2. Criterion $\mathrm{J}$ for different values of the parameter STLEVAMF in BAÏKAL, ranging from 0 to 400 degree-days.

than for wheat and maize. This is consistent with the high water requirements of linseed reported by Plonka and Anselme [23]. The depth where the root density is half of the surface root density (ZPENTE) was almost twice deeper for wheat and maize than for linseed. This is consistent with the well-known poor ability of linseed roots to explore the soil.
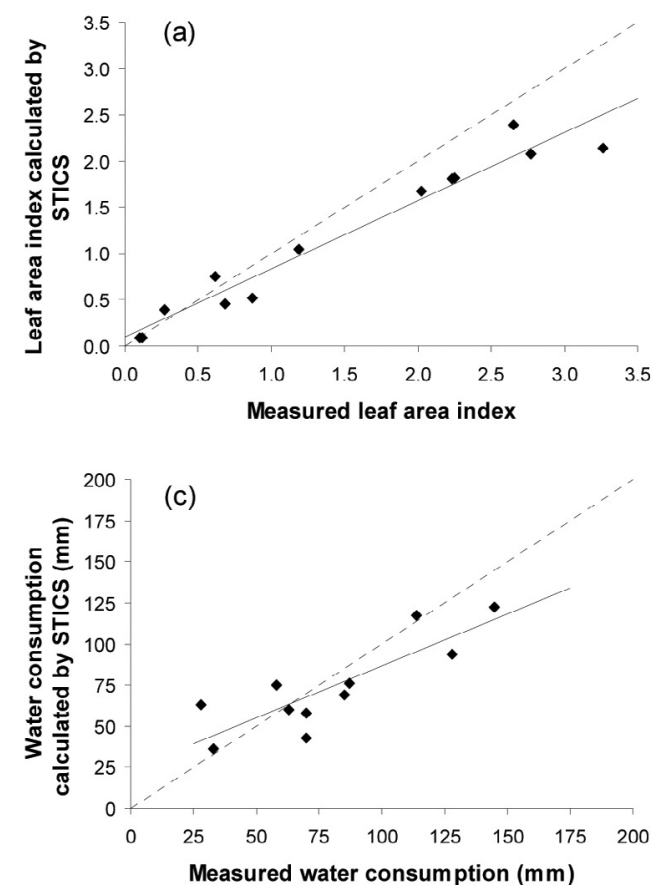

- Data - Reg. $-\cdots \mathrm{X}=\mathrm{Y}$

Figure 4. Comparison between calculations by STICS and measurements used for calibration: (a) leaf area index (values for BAÏKAL, slope = 0.74 , intercept $=0.09$, coefficient of determination $=0.95$ ); (b) biomass in tons ha ${ }^{-1}$ ( spring and winter linseed, slope $=0.91$, intercept $=-0.18$, coefficient of determination $=0.95$ ); (c) water consumption by the crops in mm between two dates of soil moisture observations (spring and winter linseed, slope $=0.63$, intercept $=23.43$, coefficient of determination $=0.71)$; (d) total plant nitrogen content in $\mathrm{kg} \mathrm{ha}^{-1}($ spring and winter linseed, slope $=1.10$, intercept $=-4.84$, coefficient of determination $=0.94$ ).

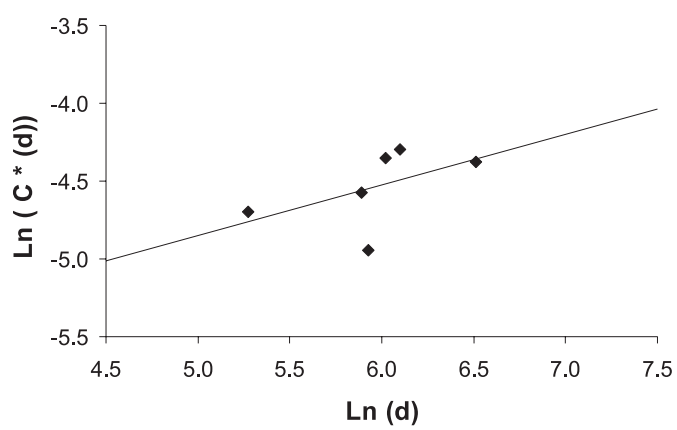

Figure 3. Linear relationship between the logarithm of $C^{*}(d)$ and the logarithm of the number of plants per square meter (d) to calculate the parameters of leaf growth for BAÏKAL. The slope of the linear regression is 0.324 , the intercept is -6.47 and the coefficient of determination is 0.27 .

\subsection{Comparison between simulations and measurements used to calibrate the model}

Simulations by STICS were compared with measurements in the three main experiments used for calibration (2, 4 and 6), for the main variables in linseed production: leaf area, plant biomass, water consumption, plant nitrogen content, seed number
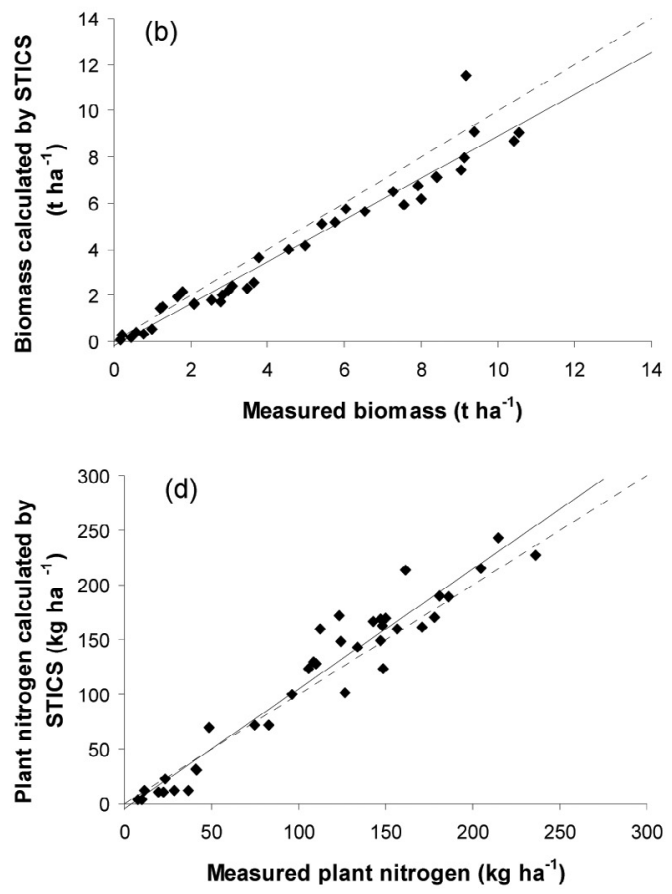
and seed yield. The comparison with the experiments without irrigation (1, 3 and 5) is not shown because no water stress occurred. Thus, the results were similar to those in irrigated experiments (2, 4 and 6). Figure 4a presents the results for leaf area index. There was a close relationship between calculations and measurements. However, the slope of the regression is only 0.74. This means that STICS underestimated leaf area. The high values of LAI measurements were the most underestimated. The calculations of biomass by STICS and the measurements were in good agreement (Fig. 4b). There was only a slight underestimation of biomass by the model. More discrepancies between calculations and measurements were found for water consumption (Fig. 4c): the coefficient of determination was only 0.71 . Moreover, the slope and the intercept were far from 1 and 0 , respectively. However, a high value for the intercept compensated a low value for the slope. Overall, there was little bias of the model for water consumption. The sum of the calculated values was only $8 \%$ less than the sum of the measurements. Plant nitrogen content was well calculated by STICS (Fig. 4d). There was only a slight overestimation by the model. The calibration of seed set and seed filling was only done with the measurements on NIAGARA sown at dates 1 and 2 (see Materials and Methods). Hence, the simulations of seed number and seed yield were only compared with the measurements for these treatments (Tab. IV). No regression was done between calculated and measured values, because the ranges of measured seed numbers and seed yields were not large enough. Seed numbers and seed yields were slightly underestimated by STICS, by about $10 \%$.

\subsection{Validation of the model by comparing simulations and measurements not used to calibrate the model}

The emergence module was not calibrated for linseed. In simulations to validate the model, the date of emergence was an input variable. Simulations by STICS were compared with measurements in experiments 9 to 13, which were not used for calibration.

The main variables in linseed production were compared, except water consumption because of lack of measurements: leaf area, plant biomass, plant nitrogen content, seed number and seed yield. The values of the statistical criteria to validate the model are reported in Table V. The calculated leaf area indices were correlated to the measurements, but the values were lower (Fig. 5a). The underestimation by STICS was similar to that observed with the experiments used for calibration (see the slopes and the intercepts). The mean deviation, of about $-18 \%$, indicates that the underestimation was not too great, while the RMSE was almost 50\%, suggesting a large scattering. The discrepancies between calculations and measurements at low plant densities were different from the rest of the data set. When leaf area index was low, until flowering, there was a great overestimation by the model. Then, leaf area was underestimated. The STICS model simulated pretty well the plant biomass (Fig. 5b). The slope and the intercept of the regression were different from 1 and 0 , respectively, but it was mainly due to an overestimation by the model at low plant densities in experiment 10 . The good agreement between calculations and measurements for most data resulted in a mean deviation close to

Table IV. Comparison between seed numbers and seed yields calculated by STICS and measurements on spring linseed used for calibration.

\begin{tabular}{|c|c|c|c|c|c|c|}
\hline \multirow{2}{*}{$\begin{array}{l}\text { Experiment number } \\
\text { and location }\end{array}$} & \multirow[t]{2}{*}{ Variety } & \multirow[t]{2}{*}{ Seed density $\mathrm{m}^{-2}$} & \multicolumn{2}{|c|}{ Measurements } & \multicolumn{2}{|c|}{ Calculations by the model } \\
\hline & & & Seed number $\mathrm{m}^{-2}$ & $\begin{array}{l}\text { Seed yield } \\
\left(\mathrm{t} \mathrm{ha}^{-1}\right)\end{array}$ & Seed number $\mathrm{m}^{-2}$ & $\begin{array}{l}\text { Seed yield } \\
\left(\mathrm{t} \mathrm{ha}^{-1}\right)\end{array}$ \\
\hline \multirow{3}{*}{$\begin{array}{l}\text { Experiment } 2 \text { in } \\
\text { 'Domaine de } \\
\text { Brunehaut" }\end{array}$} & NIAGARA & 300 & 44130 & 3.76 & 36045 & 3.10 \\
\hline & & 700 & 41743 & 3.57 & 40339 & 3.47 \\
\hline & & 1100 & 52505 & 4.26 & 41969 & 3.61 \\
\hline \multirow{3}{*}{$\begin{array}{l}\text { Experiment } 4 \text { in } \\
\text { 'Domaine de } \\
\text { Brunehaut' }\end{array}$} & NIAGARA & 300 & 43905 & 3.69 & 38705 & 3.33 \\
\hline & & 700 & 47657 & 3.99 & 43797 & 3.77 \\
\hline & & 1100 & 49710 & 3.99 & 46073 & 3.96 \\
\hline Mean value & & & 46608 & 3.88 & 41155 & 3.54 \\
\hline
\end{tabular}

Table V. The values of the statistical criteria to validate the model.

\begin{tabular}{|c|c|c|c|c|c|}
\hline Criteria & Leaf area index & Total plant biomass & Total plant nitrogen content & Seed number & Seed yield \\
\hline Slope of the regression & 0.65 & 0.73 & 1.06 & 0.52 & 0.82 \\
\hline $\begin{array}{l}\text { Intercept of the } \\
\text { regression }\end{array}$ & 0.17 & 0.75 & 11 & 20842 & 1.12 \\
\hline $\mathrm{R}^{2}$ of the regression & 0.87 & 0.80 & 0.66 & 0.73 & 0.70 \\
\hline RMSE & 0.460 & 0.625 & 28.7 & 5945 & 0.745 \\
\hline RMSE in \% & 46.7 & 20.2 & 37.2 & 17.0 & 29.9 \\
\hline MD & -0.178 & -0.074 & 15.6 & 4053 & 0.670 \\
\hline $\mathrm{MD}$ in $\%$ & -18.0 & -2.4 & 20.1 & 11.6 & 26.9 \\
\hline
\end{tabular}




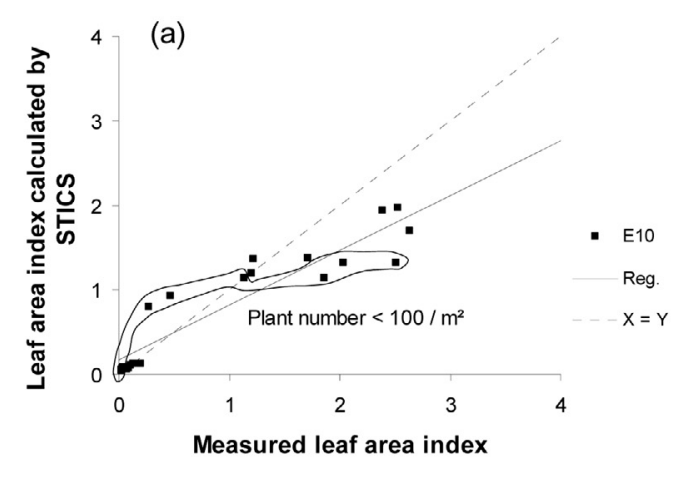

(c)

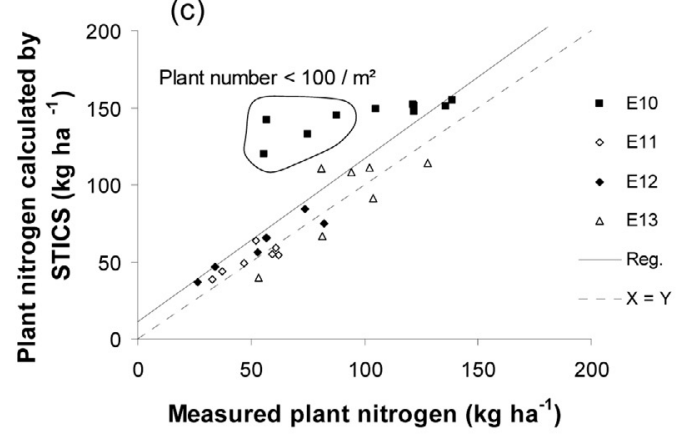

(b)

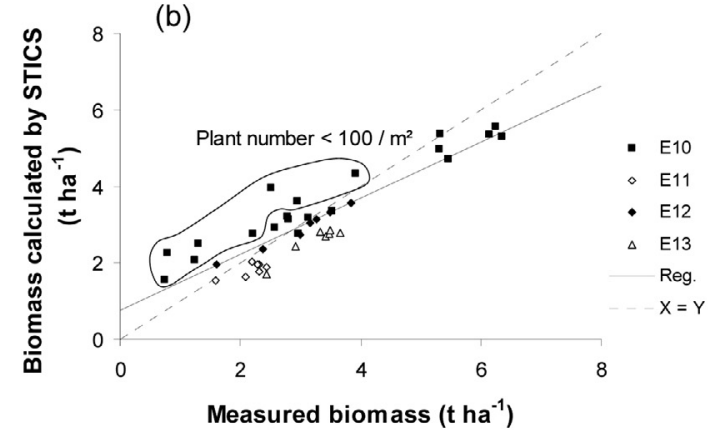

(d)

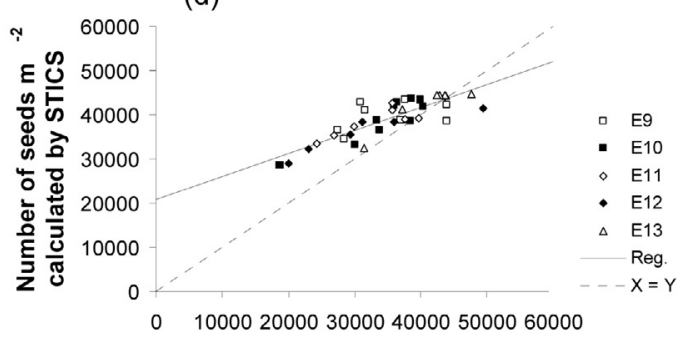

Measured number of seeds $\mathrm{m}^{-2}$

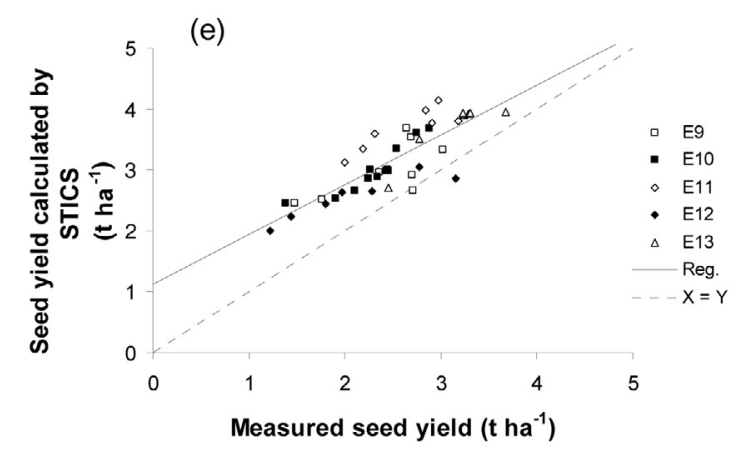

Figure 5. Comparison between calculations by STICS and measurements on spring linseed not used for calibration: (a) leaf area index; (b) total plant biomass in tons ha ${ }^{-1}$; (c) total plant nitrogen content in $\mathrm{kg} \mathrm{ha}^{-1}$; (d) number of seeds $\mathrm{m}^{-2}$; (e) seed yield in tons ha ${ }^{-1}$. The measurements were made in experiments 9 to 13 (E9 to E13).

zero and a RMSE not greater than $20 \%$. There was a close relationship between the plant nitrogen contents simulated by STICS and the measurements (Fig. 5c), except at low plant densities. For these treatments, the calculated values were two-fold greater than the measured ones. These results affected the mathematical criteria. The correlation between the calculated seed numbers and the measurements was good, but STICS overestimated this variable for the low values (Fig. 5d). Hence, the slope of the regression was low and the intercept well above zero, but the RMSE and the MD were not too far from zero. The treatments which gave these low seed numbers were: 100 seeds $\mathrm{m}^{-2}$ in Niagara in experiments 9 and 10 , no $\mathrm{N}$ fertilizer and $30 \mathrm{~kg} \mathrm{~N} \mathrm{ha}^{-1}$ in experiments 11 and 12 . The agreement with the measurements was better for the other treatments. The simulated seed yields were greater than the measured values in any treatment (Fig. 5e). However, in each experiment the effect of increasing plant number (experiments 9 and 10) or $\mathrm{N}$ availability (experiments 11 to 13 ) on seed yield was well simulated. It resulted in a slope and in a coefficient of determination not too far from 1, while the intercept was well above 0 and the mean deviation was greater than $25 \%$.

\section{DISCUSSION AND CONCLUSION}

An original procedure was developed to adapt STICS to linseed. This procedure included the methods used to adapt a model to a new crop in previous works $[1,14-16]$. However, it also included as much as possible the finding of analytic solutions for parameter determination, while in the other works the 
calibration by analogy to other crops and the testing of a range of values prevailed. Moreover, in the procedure developed for linseed, a hierarchy was proposed between these different ways of calibration. This hierarchy was based on two objectives: 1 . to use as much as possible the information on other crops, and 2. to obtain values of parameters that minimize the difference between simulation and observations. Hence, the determination of parameters by analogy was predominant, followed by the determination by measuring or calculating parameters and the testing of a range of values. These methods of calibration were preceded by an attempt to use the linseed parameters from the literature. It failed, mainly because these parameters were not exactly the same as in the STICS model. However, this information was used to determine the range of values to be tested or to check the consistency of the values of parameters with their meanings.

In the application of this procedure, the specific features of the crop and the environmental conditions were crucial. It determined the possibility of calibrating the model by analogy. For this reason, the STICS model adapted for linseed is relevant to the environmental conditions of interest (northern France). This means that a specific validation would be necessary before using this linseed model in another area. The results may indicate the need for the adaptation of some processes. For instance, a specific determination for linseed, rather than analogy to other crops, of the maximum temperatures for growth and for development could be necessary to use this model in warmer climates than in northern France. This procedure for adapting STICS to linseed could be used for other crops, or for the use of this linseed model for other environmental conditions. Depending on the features of the crop and on the environmental conditions, the balance between the different methods of calibration may be different from the work presented in this article.

The results of the application of the procedure for adapting STICS to linseed was satisfactory. There was a good agreement between simulations and measurements used to calibrate the model. This means that the STICS model and the procedure of adaptation were relevant for representing the data set. The predictive ability of the model was tested by comparing simulations with measurements not used to calibrate the model. This was also done with the STICS model for wheat and maize [3]. The values of the statistical criteria for linseed (Tab. V), wheat and maize [3] were similar. Such a comparison is a rough estimate, because the discrepancies between simulations and measurements depend on the environmental conditions of the experiments. However, much better mathematical criteria of validation for wheat and maize than for linseed would have indicated a poor relevance of the adaptation to this crop. Much discrepancy between simulations and measurements could be attributed to bad simulations at very low plant densities and to the lack of simulation of the effects of fungus and lodging by STICS. The difficulty of simulating very low plant densities probably resulted from the choice of the option of simulating the canopy as homogeneous. This hypothesis is not relevant at low plant densities. Because of similar values of statistical criteria between linseed, wheat and maize, and because most of the discrepancies probably resulted from the inability of STICS to simulate some processes, it is concluded that the adaptation was successful. However, this does not mean that this model could be used without further improvement for crop management.

The results of the calibration and the validation of STICS give information about the possibility of using this model. It was calibrated for cool and humid climates and at a latitude where no photoperiod effect on crop development was detected. The model was then validated with five experiments not used for calibration. This was not enough. Further validation is needed in order to know better the possible utilizations of the STICS model for linseed. The results of the adaptation of STICS suggest that the simulations of the model are reliable in a range of conditions which are the ones that prevail for this crop: a cool and humid climate, sowing in March or early April, and plant density above $100 \mathrm{~m}^{-2}$. However, some processes which are very important for linseed are not simulated by STICS: the loss of seeds during emergence, fungus diseases and lodging. Poor efficiency of nitrogen fertilizer is also a major problem of linseed crops. It can result from problems of root growth, of nitrogen immobilization by micro-organisms or nitrogen loss by leaching, volatilization or denitrification. The linseed STICS model was not able to account for this poor efficiency of nitrogen fertilizer. It may have arisen from the lack of simulation of denitrification by STICS 4.0, and from the difficulty of simulating problems of root growth due to soil structure with this model (it can only be taken into account by a reduction of the root maximum depth). This greatly reduces the possible utilizations of the linseed STICS model. However, the present work must be seen as a first step towards using a model to improve linseed crop management.

When further validated, the linseed STICS model will be used to help to diagnose yield-limiting factors. This information is needed to find new ways to improve crop management. The model will give information about the occurrence of climatic limiting factors and nitrogen stress when there is no problem of fertilizer-use efficiency. Moreover, the difference between simulated and measured yield will be attributed to the problems not simulated (poor efficiency of nitrogen fertilizer, diseases or lodging) if they are observed in the fields. A crop model is also needed to investigate a range of crop management such as plant density. However, this will not be relevant as long as the main limiting factors are not taken into account. The priority is to improve the simulation of poor nitrogen-fertilizer efficiency and to simulate the effects of fungus diseases and lodging. The new version of STICS provides a better simulation of the loss of nitrogen. It should help to take into account poor nitrogen-fertilizer efficiency. However, this version does not simulate fungus diseases or lodging. As far as we know, other crop models do not account for these problems either. In the future, this should be a priority in order to use crop models to investigate crop management. There is also a need for the simulation of the loss of seeds during emergence. This will be done by connecting STICS with the SIMPLE model [10] which simulates processes from sowing to emergence as affected by temperature, moisture and soil structure.

Acknowledgements: The authors wish to thank the "Conseil Régional de Picardie" and "Office National Interprofessionnel des Oléagineux, protéagineux et cultures textiles" for their financial support. 


\section{APPENDIX 1. List of symbols}

\begin{tabular}{|c|c|c|}
\hline Symbol & Meaning of the symbol & Units \\
\hline ADENS & parameter of compensation between stem number and plant density & no unit \\
\hline ADIL & parameter of the critical curve of nitrogen needs & g N g dry matter ${ }^{-1}$ \\
\hline ADILMAX & parameter of the maximum curve of nitrogen needs & g N g dry matter ${ }^{-1}$ \\
\hline $\mathrm{AMF}$ & the day of maximum acceleration in the growth of LAI & days \\
\hline BDENS & maximum density above which there is competition between plants & plants $\mathrm{m}^{-2}$ \\
\hline BDIL & parameter of the critical curve of nitrogen needs & no unit \\
\hline BDILMAX & parameter of the maximum curve of nitrogen needs & no unit \\
\hline CGRAIN & slope of the relationship between grain number and growth rate during the NBJGRAIN before stage DRP & grains g dry matter ${ }^{-1}$ day \\
\hline CGRAINV0 & number of grains produced when growth rate is zero & grains $\mathrm{m}^{-2}$ \\
\hline CROIRAC & growth rate of the root front & $\mathrm{cm}$ degree-day ${ }^{-1}$ \\
\hline $\mathrm{d}$ & plant density & plants $\mathrm{m}^{-2}$ \\
\hline DELTAI & daily increase in the leaf area index & $\mathrm{m}^{2}$ leaves $\mathrm{m}^{-2}$ soil day ${ }^{-1}$ \\
\hline DENSITE & plant density & plants $\mathrm{m}^{-2}$ \\
\hline DLAIMAX & maximum rate of the setting up of LAI & $\mathrm{m}^{2}$ leaves $\mathrm{m}^{-2}$ soil degree-day ${ }^{-1}$ \\
\hline DRP & the first day of seed filling & days \\
\hline EBMAX & $\begin{array}{l}\text { maximum radiation-use efficiency = EFCROIJUV, EFCROIREPRO or EFCROIVEG, depending on } \\
\text { the stage of development of the crop }\end{array}$ & $\mathrm{tha}^{-1} \mathrm{MJ}^{-1} \mathrm{~m}^{2}$ \\
\hline EFCROIJUV & maximum radiation-use efficiency during the juvenile phase & $\mathrm{g} \mathrm{MJ}^{-1}$ \\
\hline EFCROIREPRO & maximum radiation-use efficiency during the grain filling phase & $\mathrm{g} \mathrm{MJ}^{-1}$ \\
\hline EFCROIVEG & maximum radiation-use efficiency during the vegetative phase & $\mathrm{g} \mathrm{MJ}^{-1}$ \\
\hline EXTIN & extinction coefficient of the photosynthetic active radiation in the canopy & no unit \\
\hline HI & Harvest index & no unit \\
\hline INNMIN & minimum value of nitrogen stress index & no unit \\
\hline IRMAX & maximum value of harvest index & no unit \\
\hline $\mathrm{J}$ & The sum of the squares of differences between simulations and measurements & the unit of the variable ${ }^{2}$ \\
\hline KMAX & maximum crop coefficient for water requirements & no unit \\
\hline LAI & leaf area index & $\mathrm{m}^{2}$ leaves $\mathrm{m}^{-2}$ soil \\
\hline LAN & the day when $\mathrm{LAI}=0$ & days \\
\hline LAX & the first day of maximum LAI & days \\
\hline LEV & the day of seedling emergence & days \\
\hline MASECNMAX & maximum plant biomass before the decrease in the critical curve of nitrogen needs & $\mathrm{tha}^{-1}$ \\
\hline MAT & physiological maturity & days \\
\hline MD & The mean deviation of a simulated variable compared with the measurements & the unit of the variable \\
\hline NBJGRAIN & number of days to compute the number of grains & days \\
\hline PGRAINMAXI & maximum weight of one grain ( $0 \%$ of water content) & $\mathrm{g}$ \\
\hline PROPPFZ & root activity for soil water content below the wilting point & no unit \\
\hline PSISTO & absolute value of the potential of stomatal closing & bars \\
\hline PSITURG & absolute value of the potential of the beginning of decrease in the cellular extension & bars \\
\hline RMSE & The root mean square error of a simulated variable compared with measurements & the unit of the variable \\
\hline SEN & the first day of decrease in LAI & days \\
\hline SBV & leaf area to leaf biomass ratio & $\mathrm{cm}^{2} \mathrm{~g}^{-1}$ \\
\hline STAMFLAX & sum of development units between the stages AMF and LAX & degree-days \\
\hline STDRPMAT & sum of development units between the stages DRP and MAT & degree-days \\
\hline STLAXSEN & sum of development units between the stages LAX and SEN & degree-days \\
\hline STLEVDRP & sum of development units between the stages LEV and DRP & degree-days \\
\hline STLEVAMF & sum of development units between the stages LEV and AMF & degree-days \\
\hline STSENLAN & sum of development units between the stages SEN and LAN & degree-days \\
\hline $\mathrm{T}_{\mathrm{c}}$ & sum of development units between the stages LEV and AMF & degree-days \\
\hline TCMAX & maximum temperature of growth & ${ }^{\circ} \mathrm{C}$ \\
\hline TCMIN & minimum temperature of growth & ${ }^{\circ} \mathrm{C}$ \\
\hline TCOPT & optimum temperature of growth & ${ }^{\circ} \mathrm{C}$ \\
\hline TAIR & daily average air temperature & ${ }^{\circ} \mathrm{C}$ \\
\hline TDMAX & maximum temperature for development & ${ }^{\circ} \mathrm{C}$ \\
\hline TDMIN & minimum temperature for development & ${ }^{\circ} \mathrm{C}$ \\
\hline UDEVAIR & effective temperature for the development, computed with TAIR & ${ }^{\circ} \mathrm{C}$ \\
\hline ULAI & physiological time units for the calculation of leaf area index between the stages LEV and LAX & no unit \\
\hline VITICARB & rate of increase in the harvest index & g of grain g plant ${ }^{-1}$ day $^{-1}$ \\
\hline VMAX2 & rate of rapid nitrogen absorption for the low affinity system & $\mu \mathrm{mol} \mathrm{cm} \mathrm{cm}^{-1} \mathrm{~h}^{-1}$ \\
\hline ZPENTE & depth where the root density is half of the surface root density for the reference profile & $\mathrm{cm}$ \\
\hline ZPRLIM & maximum depth of the root profile for the reference profile & $\mathrm{cm}$ \\
\hline
\end{tabular}




\section{APPENDIX 2. Calculation of the analytic solution for the parameters of leaf expansion}

If no nitrogen or water stress occurs, the daily increase in leaf area index (DELTAI) is calculated as follows:

$$
\begin{gathered}
\operatorname{DELTAI}(n)=\frac{D \operatorname{LAIMAX}}{1+\exp (5.5 \times(2.2-U L A I(n)))} \\
\times(\operatorname{TAIR}(n)-\operatorname{TCMIN}) \times \operatorname{DENSITE} \times\left(\frac{D E N S I T E}{B D E N S}\right)^{A D E N S}
\end{gathered}
$$

$\mathrm{n}$ : the number of the day;

$\operatorname{TAIR}(\mathrm{n})$ : mean air temperature on day n;

DENSITE: plant density:

DLAIMAX: the parameter of the maximum rate of the setting up of LAI;

TCMIN: the parameter of the minimum temperature for growth;

ADENS: the parameter of the compensation between stem number and plant density;

BDENS: the parameter of the maximum density above which there is competition between plants.

From emergence (em) to the stage of development AMF, the physiological time unit is calculated as follows:

$$
\operatorname{ULAI}(n)=\frac{\sum_{i=e m}^{i=n}(\operatorname{TAIR}(i)-T C M I N)^{+}}{S T L E V A M F} \times 1.2+1 .
$$

From AMF to the maximum LAI (stage of development LAX):

$\operatorname{ULAI}(n)=\frac{\sum_{i=e m}^{i=n}(\operatorname{TAIR}(i)-T C M I N)^{+}-S T L E V A M F}{S T A M F L A X} \times 0.8+2.2$

STLEVAMF: the parameter of the sum of temperature from emergence to the stage of development AMF;

STAMFLAX: the parameter of the sum of temperature from the stage of development AMF to LAX;

$\sum(\text { TAIR }(i)-T C M I N)^{+}$is the sum of (TAIR(i) - TCMIN) values which are above zero.

The growth in dry matter can limit the growth in leaf area, using a leaf area to biomass ratio (parameter SBV). This feedback makes the determination of parameters difficult. However, the main uses of the SBV parameter are calculation of biomass which is senescent from senescence in leaf area, and calculation of the competition between organs in indeterminate species. In linseed the calculation of the biomass which is senescent is of little interest and this species is not simulated as indeterminate. Thus, SBV was set to the very high value of $950 \mathrm{~cm}^{2} \mathrm{~g}^{-1}$, in order to avoid any feedback.
The minimum temperature for growth (TCMIN) was set to the value of the minimum temperature for development (TDMIN). The parameters ADENS, BDENS, DLAIMAX, STAMFLAX and STLEVAMF were determined in two steps. At the first step, the sum of temperature between emergence and LAX (STLEVAMF + STAMFLAX) was determined from visual observations and climatic data. Then, the sum of temperature between emergence and AMF (STLEVAMF) was determined. At the second step, the parameters ADENS, BDENS and DLAIMAX were calculated.

\section{Determination of STLEVAMF $=\mathbf{T}_{\mathrm{c}}$}

The leaf area index is calculated as the sum of DELTAI (see Eq. (1)):

$$
\operatorname{LAI}(n)=\sum_{s \leq n}\left(\frac{(\operatorname{TAIR}(s)-T C M I N)}{1+\exp (5.5 \times(2.2-U L A I(s)))}\right)^{+} \times C(d)
$$

with

$$
C(d)=D L A I M A X \times d \times\left(\frac{d}{B D E N S}\right)^{A D E N S}
$$

d: plant density.

Let us define $f_{1}(\vartheta(n))=\sum_{s \leq n}\left(\frac{(\operatorname{TAIR}(s)-T C M I N)}{1+\exp (5.5 \times(2.2-U L A I(s)))}\right)^{+}$for
$T(n) \leq T_{c}$, and $f_{2}(\vartheta(n))=\sum_{s \leq n}\left(\frac{(\operatorname{TAIR}(s)-T C M I N)}{1+\exp (5.5 \times(2.2-\operatorname{ULAI}(s)))}\right)^{+}$for $T(n)>T_{c}$ where $\vartheta(\mathrm{n})$ is a vector of TAIR(s) with s ranging from emergence to $\mathrm{n}$, and $T(n)$ is $\sum_{s \leq n}(\operatorname{TAIR}(s)-T C M I N)^{+}$.

The criterion $\mathrm{J}$ to be minimized is:

$J\left(C(d), T_{c}\right)=\sum_{n}\left(\operatorname{LAI}(n, d)_{\text {calculated }}-\operatorname{LAI}(n, d)_{\text {measured }}\right)^{2}$.

The minimum value of $\mathrm{J}$ is:

$\underset{C(d), T_{c}}{\operatorname{Min}}\left(J\left(C(d), T_{c}\right)\right)=\operatorname{Min}_{T_{c}}\left(\underset{C(d)}{\operatorname{Min}}\left(J\left(C(d), T_{c}\right)\right)\right)=\operatorname{Min}_{T_{c}}\left(J\left(C *\left(d, T_{c}\right), T_{c}\right)\right)$

where $C^{*}\left(d, T_{c}\right)$ is the value of $C(d)$ that minimizes $\mathrm{J}\left(\mathrm{C}(\mathrm{d}), \mathrm{T}_{\mathrm{c}}\right)$ for a given $T_{c}$.

(i) Solving of $\underset{C(d)}{\operatorname{Min}}\left(J\left(C(d), T_{c}\right)\right)$

$$
\begin{aligned}
& J\left(C(d), T_{c}\right)=\sum_{n / T(n) \leq T_{c}}\left(C(d) \times f_{1}(\vartheta(n))-L A I(n, d)_{\text {measured }}\right)^{2} \\
& +\sum_{n / T(n)>T}\left(C(d) \times f_{2}(\vartheta(n))-L A I(n, d)_{\text {measured }}\right)^{2}
\end{aligned}
$$




$$
\begin{aligned}
& J\left(C(d), T_{c}\right)=C^{2}(d) \times\left[\sum_{n / T(n) \leq T_{c}} f_{1}^{2}(\vartheta(n))+\sum_{n / T(n)>T_{c}} f_{2}^{2}(\vartheta(n))\right] \\
& -2 C(d) \times\left[\sum_{n / T(n) \leq T_{c}}\left(L A I(n, d)_{\text {measured }} \times f_{1}(\vartheta(n))\right)\right. \\
& \left.+\sum_{n / T(n)>T}\left(\text { LAI }(n, d)_{\text {measured }} \times f_{2}(\vartheta(n))\right)\right] \\
& +\sum_{n} L^{2} I^{2}(n, d)_{\text {measured }} \text {. }
\end{aligned}
$$

The value that minimizes the criterion is:

$$
C^{*}\left(d, T_{c}\right)=\frac{\sum_{n / T(n) \leq T}(\operatorname{LAI}(n, d))_{\text {measured }} \times f_{1}(\vartheta(n))+\sum_{n / T(n)>T}\left(L A I(n, d)_{\text {measured }} \times f_{2}(\vartheta(n))\right.}{\sum_{n / T(n) \leq T} f_{1}^{2}(\vartheta(n))+\sum_{n / T(n)>T} f_{c}^{2}(\vartheta(n))} .
$$

(ii) Solving of $\underset{T}{\operatorname{Min}}\left(J\left(C^{*}\left(d, T_{c}\right), T_{c}\right)\right)$

The criterion to minimize is:

$$
\begin{aligned}
& J\left(C *\left(d, T_{c}\right), T_{c}\right)=\sum_{n / T(n) \leq T_{c}}\left(C^{*}\left(d, T_{c}\right) \times f_{1}(\vartheta(n))-L A I(n, d)_{\text {measured }}\right)^{2} \\
& +\sum_{n / T(n)>T}\left(C^{*}\left(d, T_{c}\right) \times f_{2}(\vartheta(n))-L A I(n, d)_{\text {measured }}\right)^{2} .
\end{aligned}
$$

$T_{c}$ is independent of $d$, the plant density. Thus, the data of all densities were pooled to find the minimum value of the J criterion:

$$
J=\sum_{d} J\left(C *\left(d, T_{c}\right), T_{c}\right) .
$$

A range of value of $\mathrm{T}_{\mathrm{c}}$ were tested. The parameter STLEVAMF was set to the value of $T_{c}$ that minimized $J$.

\section{Determination of the parameters ADENS, BDENS and DLAIMAX}

The logarithm expression of equation (5) gives:

$$
\begin{aligned}
& \operatorname{Ln}(C(d))=\operatorname{Ln}(D L A I M A X)+\operatorname{Ln}(d)+A D E N S \times \operatorname{Ln}(d)-A D E N S \times \operatorname{Ln}(B D E N S) \\
& \operatorname{Ln}(C(d))=\operatorname{Ln}(D L A I M A X)-A D E N S \times \operatorname{Ln}(B D E N S)+(1+A D E N S) \times \operatorname{Ln}(d) \\
& \operatorname{Ln}(C(d))=\beta+\alpha \times \operatorname{Ln}(d) .
\end{aligned}
$$

Hence,

$$
\begin{gathered}
A D E N S=\alpha-1 \\
\beta=\operatorname{Ln}(D L A I M A X)+(1-\alpha) \times \operatorname{Ln}(B D E N S) .
\end{gathered}
$$

$C^{*}(d)$ values were calculated, for the value of $T_{c}$ that minimized equation (11), in order to determine the parameters of the linear regression: $\alpha$ and $\beta$. ADENS was then calculated.

In equation (5), it appears that the parameters DLAIMAX and BDENS are correlated to each other:

$$
\begin{aligned}
C(d) & =\text { DLAIMAX } \times d \times\left(\frac{d}{B D E N S}\right) \\
C(d) & =\text { DLAIMAX } \times d \times d^{A D E N S} \times B D E N S^{-A D E N S} \\
& =\frac{\text { DLAIMAX }}{B D E N S^{A D E N S}} \times d^{A D E N S+1} \\
& =\text { parameter } \times d^{A D E N S+1} .
\end{aligned}
$$

Hence, either DLAIMAX or BDENS must be chosen to determine the value of the other. BDENS values were chosen to take into account the meaning of this parameter : the maximum plant density above which there is a competition between plants. It was set to 14 for BAÏKAL and 21 for NIAGARA, which are the approximate number of plants above which there is a competition for light. Then, DLAIMAX was calculated:

$$
D L A I M A X=\exp (\beta+(\alpha-1) \times \operatorname{Ln}(B D E N S)) .
$$

\section{REFERENCES}

[1] Boote K.J., Mínguez M.I., Sau F., Adapting the CROPGRO legume model to simulate growth of faba bean, Agron. J. 94 (2002) 743-756.

[2] Brisson N., Mary B., Ripoche D., Jeuffroy M.-H., Ruget F., Nicoullaud B., Gate P., Devienne-Barret F., Antonioletti R., Durr C., Richard G., Beaudoin N., Recous S., Tayot X., Plenet D. Cellier P., Machet J.-M., Meynard J.-M., Delécolle R., STICS: a generic model for the simulation of crops and their water and nitrogen balances. I. Theory and parameterization applied to wheat and corn, Agronomie 18 (1998) 311-346.

[3] Brisson N., Ruget F., Gate P., Lorgeou J., Nicoullaud B., Tayot X., Plenet D., Jeuffroy M.-H., Bouthier A., Ripoche D., Mary B., Justes E., STICS: a generic model for simulating crops and their water and nitrogen balances. II. Model validation for wheat and maize, Agronomie 22 (2002) 69-92.

[4] Brisson N., Gary C., Justes E., Roche R., Mary B., Ripoche D., Zimmer D., Sierra J., Bertuzzi P., Burger P., Bussière F., Cabidoche Y.M., Cellier P., Debaeke P., Gaudillère J.P., Hénault C., Maraux F., Seguin B., Sinoquet H., An overview of the crop model STICS, Eur. J. Agron. 18 (2003) 309-332.

[5] Casa R., D’Antuono L.F., Rossini F., Simulazione della produzione del lino da olio (Linum usitatissimum L.) mediante il modello SUCROS. Applicazioni preliminari., Riv. Agron. 31 (1997) 624-633.

[6] Casa R., Russel G., Lo Cascio B., Rossini F ., Environmental effects on linseed (Linum usitatissimum L.) yield and growth of flax at different stand densities, Eur. J. Agron. 11 (1999) 267-278.

[7] Champolivier L., Merrien A., Dossier technique lin, CETIOM (Ed.), 1996, 47 p.

[8] Colson J., Dossier technique lin, CETIOM (Ed.), 1993, 94 p.

[9] D'Antuono L.F., Rossini F., Experimental estimation of linseed (Linum usitatissimum L.) crop parameters, Ind. Crops Prod. 3 (1995) 261-271. 
[10] Durr C., Aubertot J.-N., Richard G., Dubrulle P., Duval Y., Boiffin J., SIMPLE: a model for SIMulation of PLant Emergence predicting the effects of soil tillage and sowing operation, Soil Sci. Soc. Am. J. 65 (2001) 414-442.

[11] FAO, FAOSTAT database, http://apps.fao.org, 2002.

[12] Feutrie B., Noblesse E., Boddaert C., Préparer la campagne 2002, Fiche d'information destinée aux adhérents des centres de gestion $\mathrm{n}^{\circ} 19,2001,24 \mathrm{p}$.

[13] Flénet F., Kiniry J.R., Efficiency of biomass accumulation by sunflower as affected by glucose requirement of biosynthesis and leaf nitrogen content, Field Crops Res. 44 (1995) 119-127.

[14] Gabrielle B., Denoroy P., Gosse G., Justes E., Andersen M.N., Development and evaluation of a CERES-type model for winter oilseed rape, Field Crops Res. 57 (1998) 95-111.

[15] Ghiloufi M., Méthodologie d'adaptation de STICS à de nouvelles cultures : Application au tournesol et à la betterave à sucre, Mémoire pour l'obtention du Diplôme d'Agronomie Approfondie de l'INA-PG, 1999, $43 \mathrm{p}$.

[16] Hartkamp A.D., Hoogenboom G., White J.W., Adaptation of the CROPGRO growh model to velvel bean (Mucuna pruriens). I. Model development, Field Crops Res. 78 (2002) 9-25.

[17] Major D.J., Photoperiod response characteristics controlling flowering of nine crop species, Can. J. Plant Sci. 60 (1980) 777-784.

[18] Makowski D., Wallach D., Tremblay M., Using a Bayesian approach to parameter estimation; comparison of the GLUE and MCMC methods, Agronomie 22 (2002) 191-203.
[19] Marshall G., Morrison I.N., Nawolsky K., Studies on the physiology of Linum usitatissimum L.: The application of mathematical growth analysis, in: Marshall G. (Ed.), Flax: breeding and utilisation, 1989, pp. 39-47.

[20] Meijer W.J.M., van Heemst H.D.J., Bodlaender K.B.A., Waart M.V.D., Smid H.G., The development and maturing of flax, in: Marshall G. (Ed.), Flax: breeding and utilisation, 1989, pp. 48-60.

[21] Merrien A., Champolivier L., Chatenet F., Estragnat A., Segura R., Dossier technique lin, CETIOM (Ed.), 1994, 33 p.

[22] Penning de Vries F.W.T., Brunsting A.H.M., Van Laar H.H., Products, requirements and efficiency of biosynthesis: a quantitative approach, J. Theor. Biol. 45 (1974) 339-377.

[23] Plonka F., Anselme C., Les variétés de lin et leurs principales maladies cryptogamiques, INRA (Ed.), 1956, 179 p.

[24] Pujolle R., Brisson N., Écophysiologie du lin oléagineux en conditions non-limitantes, Rapport d'activité INRA Avignon, 1997, $17 \mathrm{p}$.

[25] PROLEA, Statistiques des oléagineux et protéagineux, huiles et protéines végétales 2001-2002, PROLEA (Ed.), 2002, 126 p.

[26] Ruget F., Brisson N., Delécolle R., Faivre R., Sensitivity analysis of a crop simulation model, STICS, in order to choose the main parameters to be estimated, Agronomie 22 (2002) 133-158.

[27] Sinha S.K., Tomar D.P.S., Deshmukh P.S., Bhargava S.C., Photoperiodic response and yield potential in linseed varieties, Indian J. Agric. Sci. 43 (1973) 1009-1012. 